\title{
Design of Portable EDM Machine Tool
}

\author{
Xuetao Wang \\ School of Mechanical, Electrical \& Information Engineering, SHANDONG University, WEIHAI, Shandong, Weihai, 264209, \\ China \\ 907363419@qq.com
}

\begin{abstract}
Electro Spark Erosion also known as the Electro Discharge Machining (EDM) technology is an important part of the advanced manufacturing technology and an important complement and development of machinery manufacturing in terms of mechanical cutting and grinding. EDM technology has become a significant processing method in modern production. With the constant development of manufacturing and EDM technology, a higher-level demand is put forward with regard to maneuverable, processing efficiency and processing qualify of EDM machine. Based on the research of existing electric spark processing machine tool, especially the mechanical structure, and focusing on the demand of the mechanical industry, this article designs a portable EDM machine.
\end{abstract}

Keywords-EDM; portable; machine tool; design.

\section{INTRODUCTION}

Electro Spark Erosion also known as the Electro Discharge Machining (EDM) is a processing method making use of electricity and heat. During processing period, Pulse-spark discharge is continuously generated between the electrode and the work piece. The broken tap in the hole can be removed by the high temperature instantaneously generated during the discharge. As sparks can be seen during this process, it gets its name electric spark machining.

The conventional method to remove the tap or drill is not perfect. Sometimes even after treatment, can also damage the work piece. Therefore, People look for better ways to process except the further development and improvement of the mechanical processing methods. The EDM not only meet the needs of development, but also highlighted the excellent performance. Therefore, this method obtained rapid development and wide application. The EDM in this project can be used as a portable machining tool. It is very important in some mechanical fields which is not easy to use large-scale processing equipment or difficult to machine material, wall hole and structure.

\section{PRINCIPLE OF EDM ANALYSIS}

The principle of EDM is based on an electric corrosion phenomenon, during pulse spark discharge between the tool and the work piece (positive, negative electrode). The discharge process can remove excess metal and to achieve the predetermined machining requirements on the size, shape and surface quality of the parts.
Electrical discharge machining is a controlled metal removal technique whereby an electric spark is used to cut the work piece, which takes a shape opposite to that of the cutting tool or electrode. The cutting tool (electrode) is made from electrically conductive material, usually carbon. The work piece is both submerged in a dielectric fluid, which is generally light lubricating oil. This dielectric fluid should be a nonconductor (or poor conductor) of electricity. A servo mechanism maintains a gap of about 0.0005 to 0.001 inch $(0.01$ to $0.02 \mathrm{~mm})$ between the electrode and the work, preventing them from coming into contact with each other. A direct current of low voltage and high amperage is delivered to the electrode at the rate of approximately $20000(\mathrm{~Hz})$. These electrical energy impulses become sparks which jump the dielectric fluid. Intense heat is created in the localized area of the surface of the work piece. The dielectric fluid, which is constantly being circulated, carries away the eroded particles of metal and also assists in dissipating the heat caused by the spark. The above is the basic principles of EDM. Fig1 shows it.

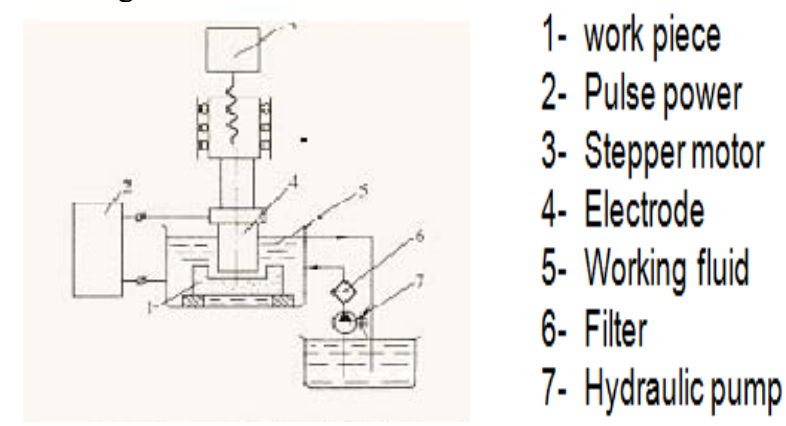

Figure 1. Basic principles of EDM

\section{Design OF HaRdWARE System}

\section{A. Mechanical structure of EDM}

Figure 2(a) show the mechanical structure of EDM and Fig.2 (b) give the exploded diagram of EDM. The structure can be divided into the two sections. 


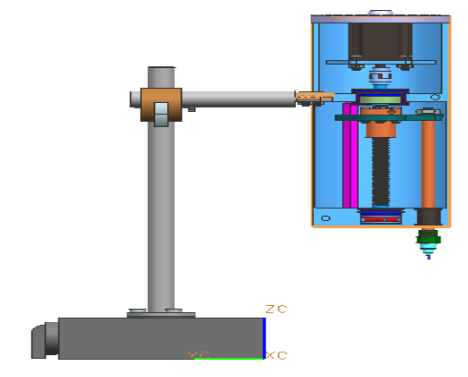

Figure 2(a). Mechanical structure of EDM

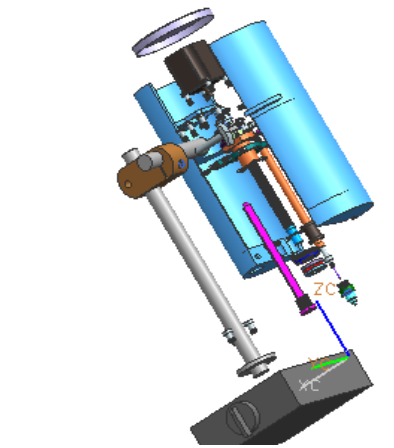

Figure 2(b). Exploded diagram of EDM

The first is the support section of EDM. comprising a base and support frame. It shown in Fig.3. The role of the base is to support the entire machine. In order to make the whole machine center of gravity down to keep the stability of machine tool, the design of base should be physical structure and the larger, heavier. It is generally Castings. The support frame of EDM is the intermediate links composed by a universal joint and the two guide rods. The guide rod and the universal device can mutually slide and respectively by a locking nut connection. As a result of a two guide rod can be linear expansion, thus realizing the working mechanism to move up and down and extending and retracting movement. In addition, the universal device can rotate, thereby driving the rotating working mechanism. It is obvious that only through the use of supporting frame, so that the mechanism realizes the three-dimensional motion.

The second is working mechanism of EDM. It shown in Fig.4. It is the whole machine core, comprising a motor, coupling, screw, nut, the tool electrode. Its working process as follows: Using the testing system to determine the position of the electrode and the work piece, and then the results are fed back to the control system. So that the pulse power output the corresponding pulse signal, stepping motor under the action of the pulse signal to do rotary motion. Coupling transmits the movement to the screw, rotary motion is converted into straight reciprocating motion. As a result of the work spindle and the working electrode with the flange nut is connected together by a connection plate, thus the electrode can moves up and down By constantly adjusting the position between electrode and work piece, until it reaches the proper position. Detection system will signal to transfer to the control system, and then make the stepping motor to stop. To conclude, this completes a work process. In the process, the machine repeats the above process automatically when the distance changes, until it reaches the most suitable position. Regardless of their size, as long as it is within the scope of processing, through the repeated work process, can complete a variety of processing.

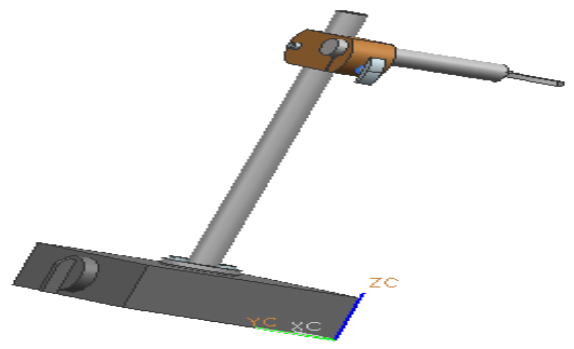

Figure 3. Support section of EDM

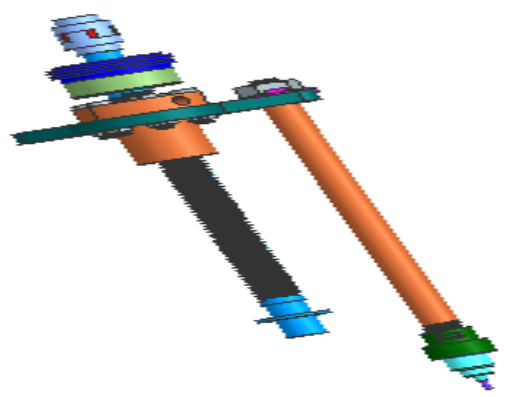

Figure 4. Working mechanism of EDM

Through the above design, not only the structure of EDM is greatly simplified, but also the processing steps are simple and the work efficiency is greatly enhanced.

\section{B. The design of working mechanism}

The design of working mechanism mainly has the following several important parts of the selection and design. (1)The type selection of Step motor (2) The choice of coupling (3) Bearing selection (4) Electrode clamp design.

The type selection of Step motor. Table I shows the main motor parameters.

TABLE I. MAIN PARAMETERS OF STEP MOTOR

\begin{tabular}{|l|l|l|l|l|l|l|l|}
\hline Type & $\begin{array}{l}\text { Step } \\
\text { angle }\end{array}$ & Voltage & $\begin{array}{l}\text { Electric } \\
\text { current }\end{array}$ & Inductance & $\begin{array}{l}\text { Static } \\
\text { moment }\end{array}$ & $\begin{array}{l}\text { Moment of } \\
\text { inertia }\end{array}$ & number \\
\hline $17 \mathrm{HM} 54$ & $0 . .9$ & $2.4 \mathrm{~V}$ & $2.4 \mathrm{~A}$ & $1.8 \mathrm{~mA}$ & $48 \mathrm{~N} . \mathrm{cm}$ & $68 \mathrm{~g} . \mathrm{cm} 2$ & 4 \\
\hline
\end{tabular}

The choice of coupling. The cross section of Plum blossom petal is usually circular, which not only can increase the load on the work surface uniformity, but also transmits large torque. Through the study of relevant knowledge and access to relevant data, quincunx elastic shaft coupling not only in the structure is relatively simple, less part number; but also its radial size is relatively small, without the need for external lubrication. In addition, the elastic element of the 
carrying capacity is higher. The elastic deformation of the element can be compensated for the relative offset of the two axes, and thus play a damping buffer role.

Based on the above analysis, combined with the power of machine tool, this design chose LMS models (GB5272-200 Instead of 2GB5272-85). Table II shows the basic parameters .

TABLE II. BASIC PARAMETERS OF COUPLING

\begin{tabular}{|l|l|l|l|l|l|l|l|}
\hline Type & Nominal torque & Diameter & D1 & D2 & Allowable speed & L1 & L2 \\
\hline LMS1 & $25 \mathrm{~N} . \mathrm{m}$ & $6 \mathrm{~mm}$ & $12 \mathrm{~mm}$ & $16 \mathrm{~mm}$ & 8500 & $21 \mathrm{~mm}$ & $13 \mathrm{~mm}$ \\
\hline
\end{tabular}

LMS1 mainly consists of two projecting teeth which closely engaged and radial compression to transmit torque. The elastic element will generate elastic deformation when the two axes are relatively offset, thereby plays a role of automatic compensation.

Bearing selection (Rolling bearing). Rolling bearing is a precision mechanical component, which turn sliding friction into rolling friction between shaft and shaft seat, thereby reducing the friction loss. The concern of a machine designer with ball and roller bearings is fivefold as follows: life in relation to load, stiffness, friction, wear and noise. For moderate loads and speeds the correct selection of a standard bearing on the basis of load rating will usually secure satisfactory performance. The deflection of the bearing elements will become important where loads are high, although this is usually of less magnitude than that of the shafts or other components associated with the bearing. Where speeds are high special cooling arrangements become necessary which may increase frictional drag. Wear is primarily associated with the introduction of contaminants, and sealing arrangements must be chosen with regard with regard the hostility of the environment.

There are many types of rolling bearings. It can be divided into radial bearing, thrust bearing, a centripetal thrust bearing, according to the different load. The radial bearing mainly bear radial force, such as deep groove ball bearing; thrust bearings only bear axial force; centripetal thrust bearing which bear the radial force and axial force.

Due to the design of EDM is a vertical machine. The two selected bearing must meet the requirements that the screw can rotate around a fixed axis in the circumferential direction and cannot have relative motion in the axial direction. Based on the stress analysis, the following two bearing is more appropriate: The following is the thrust ball bearing and the above is a deep groove ball bearing. Table III $(a / b)$ shows their parameters:

TABLE III (A). BASIC PARAMETERS OF DOWN BEARING

\begin{tabular}{|l|l|l|l|l|}
\hline Name & Code & $\begin{array}{l}\text { Bore } \\
\text { diameter }(\mathrm{d})\end{array}$ & $\begin{array}{l}\text { Outside } \\
\text { diameter (D) }\end{array}$ & width(B) \\
\hline $\begin{array}{l}\text { Thrust ball } \\
\text { bearing }\end{array}$ & 51001 & $12 \mathrm{~mm}$ & $28 \mathrm{~mm}$ & $11 \mathrm{~mm}$ \\
\hline
\end{tabular}

TABLE III (B). BASIC PARAMETERS OF UP BEARING

\begin{tabular}{|l|l|l|l|l|}
\hline Name & Code & $\begin{array}{l}\text { Bore } \\
\text { diameter } \\
\text { (d) }\end{array}$ & $\begin{array}{l}\text { Outside } \\
\text { diameter } \\
\text { (D) }\end{array}$ & width(B) \\
\hline $\begin{array}{l}\text { Deep groove } \\
\text { ball bearing }\end{array}$ & 60000 & $10 \mathrm{~mm}$ & $30 \mathrm{~mm}$ & $9 \mathrm{~mm}$ \\
\hline
\end{tabular}

Electrode clamp design. The requirement of electrode clamp design is to ensure that can not affect the work of the circumstances, to achieve the rapid installation, electrode clamping and rapid replacement. To achieve afore-mentioned requirements, the corresponding electrode clamping device is designed. Fig. 4 shows the phase two-dimensional map:

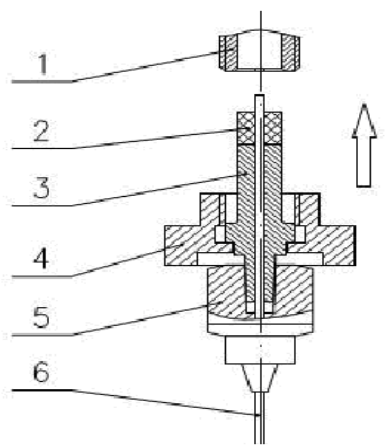

1 - Axis of rotation

2- Electrode sealing ring

3- Chuck handle

4- Lock nut

5- The stainless steel chuck

6- Electrode

Figure 4. Two-dimensional map of electrode clamp design

\section{CONCLUSION}

The EDM technology holds the important status in the manufacturing industry domain, is realizes difficultly to process the material, the complex components precise processing effective method. In this article, the design of EDM has the advantages of simple structure and easy operation. It profit from other processing technological development the success experience, enhances strong points and avoid weaknesses, uses the modern science and technology development fully the related achievement, studies the electric spark in the deep person to improve the engine bed structure and the design method. The realization intelligence control technology and the electric spark processing technology organic synthesis. Based on the above characteristics, this equipment has been widely applied in the production, as a new manufacturing method.

\section{REFERENCES}

[1] Zhou Hui, CNC EDM technology and skills. 2009, January, the first edition.

[2] Zhang Jianmin, Mechatronics system design. 2007 January first edition NO.25-29.

[3] Pu Lianggui, Ji Minggang, Mechanical design. 2005, the Eighth Edition NO.307-390.

[4] Sun Heng, Chen Zuomo, Mechanical principle. 2005, December Seventh Edition.

[5] Deng Xingzhong, Mechanical and electrical transmission control. in 2000 Edition NO.157.

[6] Tong Yu Bin , Portable electric spark processing machine, in 2004 of Shandong University. 
[7] R. Neugebauer, C. Harzbecker, A. Stoll, Parallelkinematiken imWerkzeugmaschinenbau, in: Arbeitsgenaulgkeit von Parallenlkinematiken,

vol.

2nd,

Parallelkinematik-Seminar. 